Vol. 22, No. 2, pp. 133 145, 2019.

\title{
Current Status of Nanostructured Thermoelectric Materials for Mid-High Temperature Applications
}

\author{
Woo Hyun Nam, Weon Ho Shin, Jung Young Cho, and Won-Seon Seo ${ }^{\dagger}$ \\ Energy and Environment Division, Korea Institute of Ceramic Engineering and Technology, \\ Jinju 52851, Korea
}

\section{나노구조 기반 중 · 고온용 열전소재 연구 동향}

\author{
남우현, 신원호, 조중영, 서원선 ${ }^{\dagger}$ \\ 한국세라믹기술원 에너지환경본부
}

(Received June 7, 2019; Accepted June 17, 2019)

\begin{abstract}
s
Thermoelectric energy conversion has attracted much attention because it can convert heat into electric power directly through solid state device and vice versa. Current research is aimed at increasing the thermoelectric figure of merit $(Z T)$ by improving the power factor and reducing the thermal conductivity. Although there have been significant progresses in increasing $Z T$ of material systems composed of $\mathrm{Bi}, \mathrm{Te}, \mathrm{Ge}, \mathrm{Pb}$, and etc. over the last few decades, their relatively high cost, toxicity, and the scarcity have hindered further development of thermoelectrics to expand practical applications. In this paper, we review the current status of research in the fields of nanostructured thermoelectric materials with eco-friendly and low cost elements, such as skutterudites and oxides, for mid-high temperature applications, highlighting the strategies to improve thermoelectric performance.
\end{abstract}

Keywords: Thermoelectricity, Skutterudite, Oxide, Mid-high temperature

\section{1. 서론}

열전현상(thermoelectric effect)은 어떠한 구동장치 없이 열과 전기가 고체 상태의 소재 내에서 직접 변환되 는 기술로 버려지는 폐열을 활용한 열전발전 및 무 냉매 전자냉각 등에 다양하게 활용될 수 있는 친환경 에너지
기술이다. 이러한 열전변환 기술은 Fig. 1에 나타낸 것 같 이 높은 에너지를 가지는 열원(heat source) 영역의 전하 가 저온 영역으로 이동하면서 유발하는 열기전력 (thermopower)에 의해 전류가 흐르게 되는 제벡 (Seebeck) 효과(Fig. 1(a))와 전류의 흐름에 의해 전하가 열을 가지고 이동하면서 능동 냉각(active cooling)을 구 

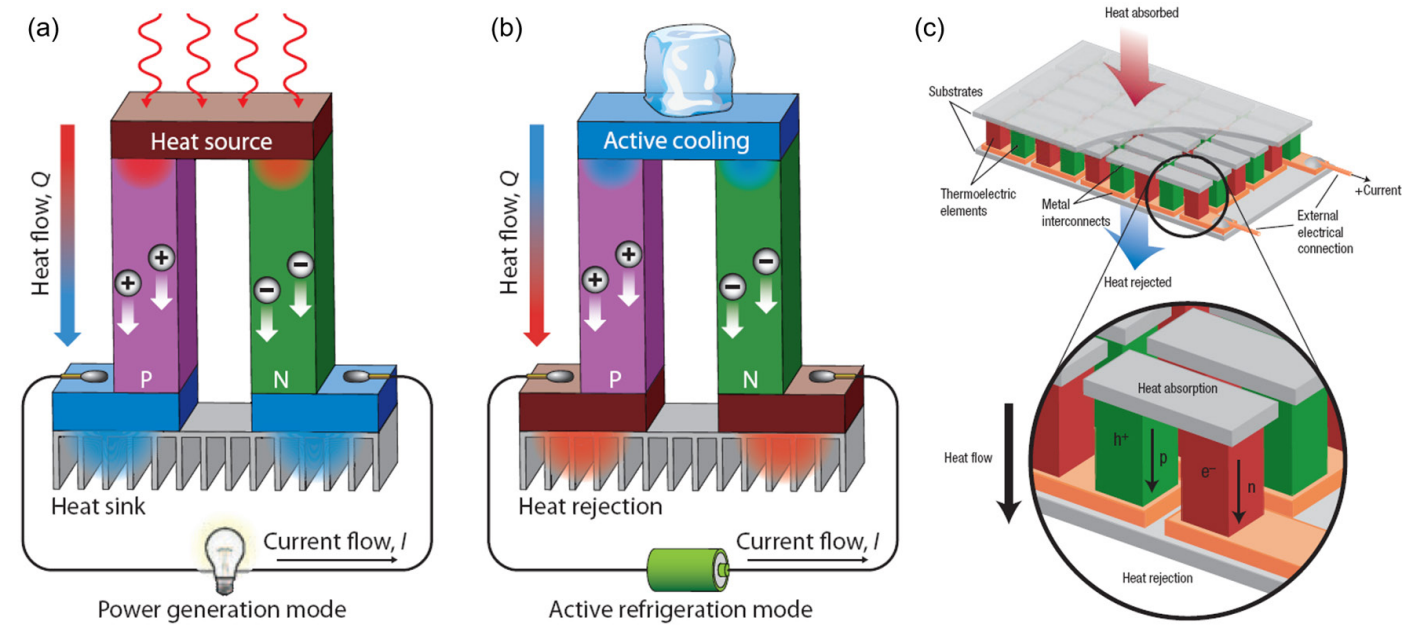

Fig. 1. (a) 제벡 효과와 (b) 펠티어 효과의 기본 원리"). (c) 직렬로 연결된 $n$-type과 $p$-type 열전소재와 전극으로 구성된 열전모듈의 모식도2).

현하는 펠티어(Peltier) 효과(Fig. 1(b))에 기반한다1). 제 벡 효과에 기반한 열전발전 및 펠티어 효과에 기반한 열 전냉각을 포함하는 열전변환은 모두 직렬로 연결된 $n$ 형 및 $p$ 형의 열전소재와 전극으로 구성된 모듈의 형태로 구 현된다(Fig. 1(c) $)^{2)}$.

이와 같이 단순한 구성으로 인하여 열전모듈의 효율은 모듈을 구성하고 있는 열전소재의 성능에 크게 의존하는 특징을 가진다. 열전소재의 성능을 나타내는 열전성능지 수(dimensionless thermoelectric figure of merit, $Z T)$ 는 다음과 같이 표현된다.

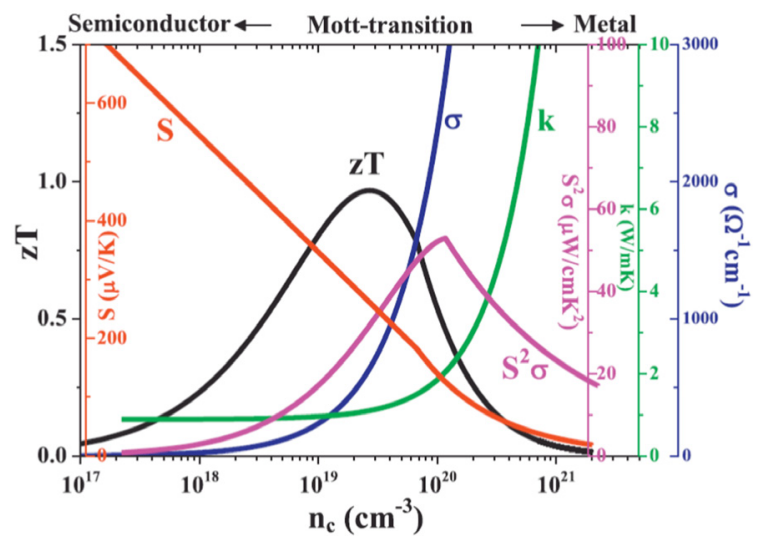

Fig. 2. 열전성능지수를 구성하는 인자들의 상관관계를 나타내는 모 식도 ${ }^{3)}$.

$$
Z T=S^{2} \sigma T / \kappa,
$$

여기서 $S$ 는 제벡계수, $\sigma$ 는 전기전도도, $T$ 는 절대온도, 그리고 $\kappa$ 는 열전도도를 나타낸다.

열전소재의 성능지수 향상을 위해서는 전기전도도와 제벡계수의 증가와(파워팩터 $\left(S^{2} \sigma\right)$ 의 증가) 동시에 열전 도도의 감소가 필수적이지만, Fig. 2과 같이 일반적으로 전기전도도 $(\sigma=n q \mu$, 여기서 $n$ 은 캐리어 농도, $q$ 는 전하 량, $\mu$ 는 이동도)와 제벡계수는 Pisarenko relation $(S \propto$ $\left.n^{-2 / 3}\right)$ 에 의해 서로 반비례 관계를 가지고, 전기전도도와 열전도도는 Wiedermann-Franz $\operatorname{law}\left(\kappa=\kappa_{1}+\kappa_{\mathrm{e}}=\kappa_{1}\right.$ $+L \sigma T$, 여기서 $\kappa_{1}$ 은 포논에 의한 열전도도, $\kappa_{\mathrm{e}}$ 는 전하에 의한 열전도도, $L$ 은 로렌츠 넘버)에 의해 비례 관계를 가 지고 있어 동시에 세 가지 인자를 조절하여 열전성능지수 를 향상시키기는 쉽지 않달. 2000 년대 까지는 $Z$ TT값이 1.0 정도의 수준에 머물렀으나, 그 이후 급속도로 발전한 나노기술이 $Z T$ 값을 구성하는 인자 간의 상관관계를 약화 시킴으로써 2.0 정도의 $Z T$ 값을 보이는 소재들이 여러 온 도 범위에서 보고되고 있다.

열전성능지수를 구성하는 인자는 사용하는 열전소재 에 따라 그 값이 달라질 뿐만 아니라, 하나의 열전소재에 서도 사용하는 온도에 따라 각 인자들의 값이 변화하게 되므로 Fig. 3에서와 같이 열전소재의 성능지수인 $Z T$ 는 온도의 함수로 나타나게 된다. $\mathrm{Bi}_{2} \mathrm{Te}_{3}$ 계 열전소재는 상온 
(a)

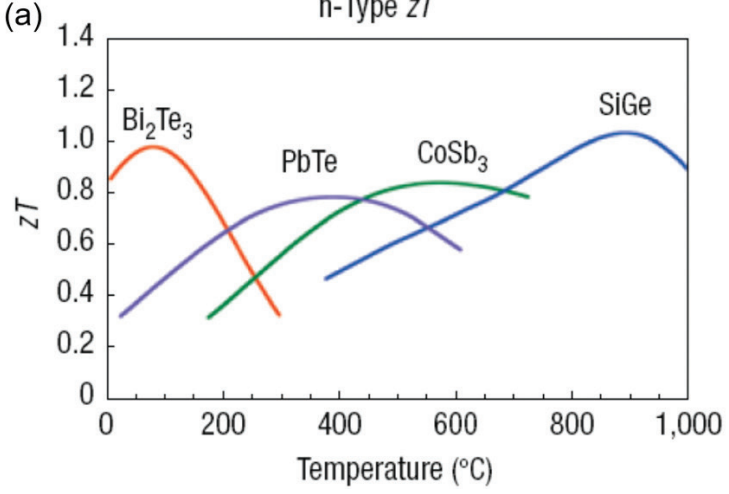

(b)

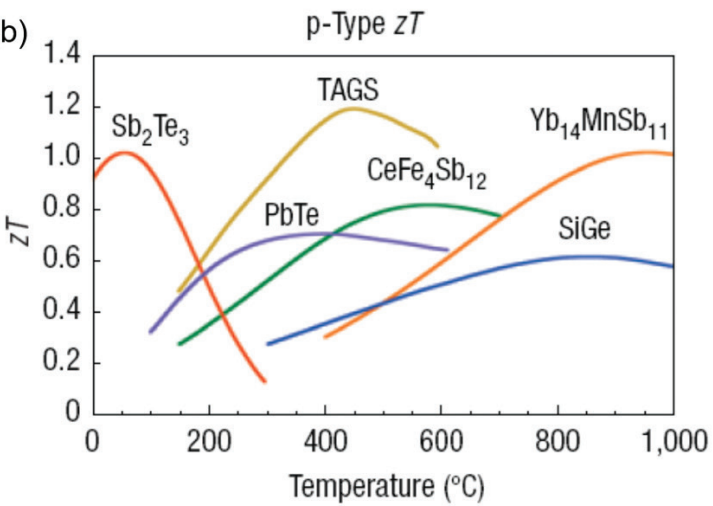

Fig. 3. 대표적인 (a) n-type 및 (b) p-type 열전소재의 온도에 따른 열전성능지수, $Z T^{2)}$.

에서부터 $500 \mathrm{~K}$ 근처의 온도에서 우수한 열전성능을 나 타내는 유일한 저온용 열전소재로 $\mathrm{Bi}_{2} \mathrm{Se}_{3}$ 또는 $\mathrm{Sb}_{2} \mathrm{Te}_{3}$ 와 합금화를 통해 각각 $n$ - 및 $p$-type의 구현이 가능하다. $500 \sim 750 \mathrm{~K}$ 의 중온 영역에서는 $\mathrm{CoSb}_{3}$ 계, $\mathrm{PbTe}$ 계, Silicide계 등이 우수한 열전성능을 나타내며, $750 \mathrm{~K}$ 이 상의 고온 영역에서는 $\mathrm{SiGe}$ 계 열전소재가 우수한 열전성 능을 나타낸다2).

하지만, 현재 우수한 성능을 나타내는 대부분의 열전소 재들은 $\mathrm{Bi}, \mathrm{Te}, \mathrm{Ge}$ 등의 희소원소 및 $\mathrm{Pb}$ 등의 독성원소 를 포함하고 있어, 이를 대체할 수 있는 신조성 열전소재 의 개발이 요구되고 있다. 예를 들어, 저온용 $\mathrm{Bi}_{2} \mathrm{Te}_{3}$ 계 열 전소재는 $100 \$ / \mathrm{kg}$ 의 고가 소재이며, 중온용 열전소재인 $\mathrm{PbTe}$ 는 유해원소인 $\mathrm{Pb}$ 와 희소원소인 $\mathrm{Te}$ 로 구성되어 있 고, 고온용 $\mathrm{SiGe}$ 계 열전소재는 $\mathrm{Ge}$ 의 희소성으로 인하여 $670 \$ / \mathrm{kg}$ 정도의 고가 소재이다. 따라서, 열전소자 시장 의 확대를 위해서는 유해원소와 희소원소가 배제된 원료 를 사용하면서도 우수한 $Z T$ 를 가진 열전소재의 원천기 술 개발이 매우 중요하다.

한편, 열전발전은 산업 폐열, 수송 배폐열, 인체열, 태 양열, 지열 등 다양한 형태로 분산되어 존재하는 광범위 한 온도의 열원에 적용이 가능한 기술로. 여기서 인체열 을 제외한 대부분의 영역이 중 - 고온 영역에 해당하기 때 문에, 중·고온 열전발전 모듈 개발의 응용범위와 시장성 이 아주 높다. 최근 미국, 독일, 중국을 중심으로 skutterudite계 열전발전 모듈의 상용화 가능성이 발표
되고 있어, 보다 더 다양한 온도영역의 폐열을 활용할 수 있을 것으로 기대된다. 상기 다양한 형태의 열전발전 응 용을 위한 열전발전 모듈의 상용화를 위해서는 중· 고온 영역에서의 고효율 열전소재기술 개발이 시급한 상황이 다. 이러한 점을 바탕으로, 본고에서는 중· 고온용 열전 소재로 활발히 연구되고 있는 skutterudite계, 산화물계 열전소재기술의 연구동향을 소개하고자 한다.

\section{Skutterudite계 열전소재기술 동향}

1995년에 Slack은 열전성능지수를 구성하는 인자들의 상관관계를 약화시켜 열전성능을 향상시키기 위해 PGEC(Phonon-Glass Electron-Crystal) 개념을 제안 하였다 ${ }^{4}$. 이는 열전달을 담당하는 포논의 움직임은 차단 하고(Phonon-Glass) 전하의 이동은 방해하지 않게 하 여(Electron-Crystal) $\sigma / \kappa$ 비율의 증대를 통해 열전성능 지수를 향상시킨다는 전략이다. $\mathrm{MX}_{3}(\mathrm{M}=\mathrm{Co}, \mathrm{Rh}$, 또는 $\mathrm{Ir} ; \mathrm{X}=\mathrm{P}, \mathrm{As}$, 또는 $\mathrm{Sb})$ 의 화학식을 가지는 2 원계 skutterudite 화합물은 Fig. 4(a)에 나타낸 것처럼 단위 격자 내에 두 개의 void를 포함하는데 ${ }^{5)}$, rattler라 불리는 이종원자를 void에 채워 다른 원자들과는 독립적으로 진 동시키는 rattling 효과를 유발하여 격자열전도도를 감 소시킬 수 있다(Fig. 4(b) $)^{6}$. 이러한 관점에서 skutterudite계 소재는 rattling 효과에 의해 PGEC 개 념의 실현이 가능한 물질로서 많은 연구가 진행되어 왔으 
(a)

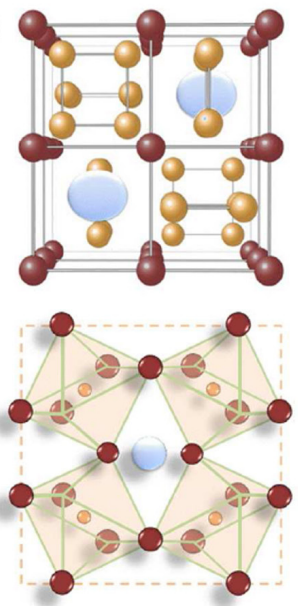

(b)

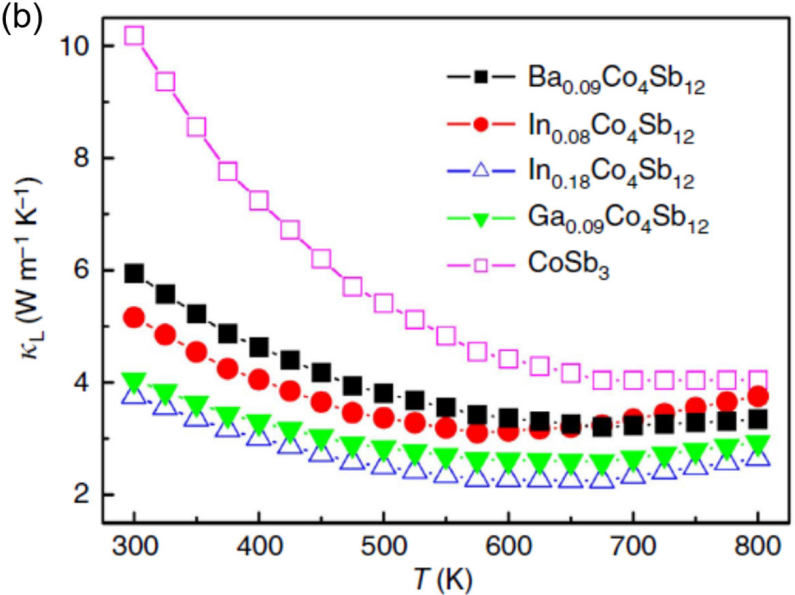

Fig. 4. (a) Skutterudite계 열전소재의 결정구조 (빨간 구는 $\mathrm{Co}$, 노란 구는 Sb, 파란 구는 void 또는 rattler를 나타냄)5). (b) Rattling 효과를 이용 한 포논 산란을 통한 Skutterudite계 소재의 열전도도 제어하.

며, 특히 skutterudite계 소재 중에서도 $\mathrm{CoSb}_{3}$ 는 $0.2 \mathrm{eV}$ 의 적절한 밴드갭 에너지와 높은 캐리어 이동도를 가지고 있고 친환경 저가 원소로 구성되어 있어 중온용 열전소재 로 적합하다.

$\mathrm{CoSb}_{3}$ 계 소재에서 rattling 효과의 극대화를 통한 열 전성능지수 향상을 위해 rattler의 종류와 filling rate에 대한 연구가 진행되었는데, 2016년에 S. Wang은 Yb가 void의 일부에 채워진 $n$-type single-filled $\mathrm{Yb}_{0.3} \mathrm{Co}_{4} \mathrm{Sb}_{12}$ 를 제작하여 $850 \mathrm{~K}$ 에서 $Z T=1.5$ 를 보고하였닥) 2011
년에 X. Shi는 triple-filled $\mathrm{CoSb}_{3}$ 화합물이 single-, double-filled $\mathrm{CoSb}_{3}$ 화합물과 비교했을 때 가장 낮은 격자열전도도를 가진다는 것을 밝혀내었으며(Fig. 5), 그 결과 $\mathrm{Ba}, \mathrm{La}, \mathrm{Yb}$ 이 첨가된 $n$-type $\mathrm{Ba}_{0.08} \mathrm{La}_{0.05} \mathrm{Yb}_{0.04}$ $\mathrm{Co}_{4} \mathrm{Sb}_{12}$ 샘플에서 $Z T=1.7(850 \mathrm{~K})$ 을 보고하였다8).

Rattling 효과 외에도 $\mathrm{CoSb}_{3}$ 계 소재의 열전도도 제어 를 위해 격자 산란을 유도하는 방법으로 나노구조체를 적 용하는 방법도 고려되었다. 2015년에 L. Fu는 Nidoped $\mathrm{Yb}_{0.2} \mathrm{Co}_{4} \mathrm{Sb}_{12}$ 분말을 소결하여 $\mathrm{Ni}$ 나노결정립이
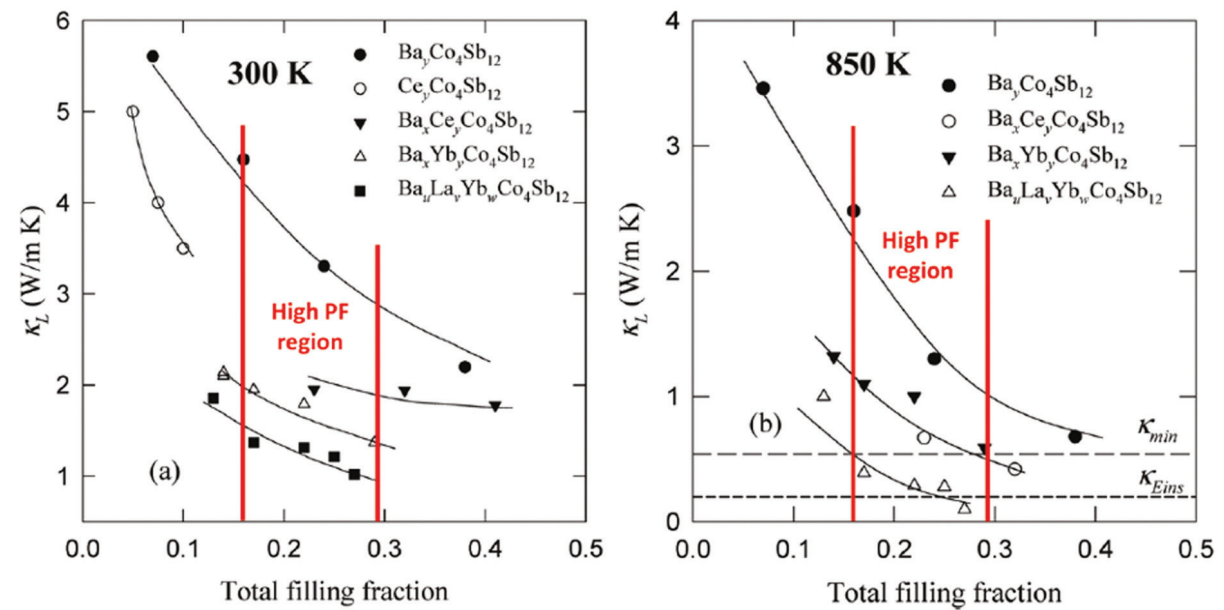

Fig. 5. Rattler filling fraction에 대한 $\mathrm{CoSb}_{3}$ 계 소재의 격자열전도도 변화 ${ }^{8)}$. 


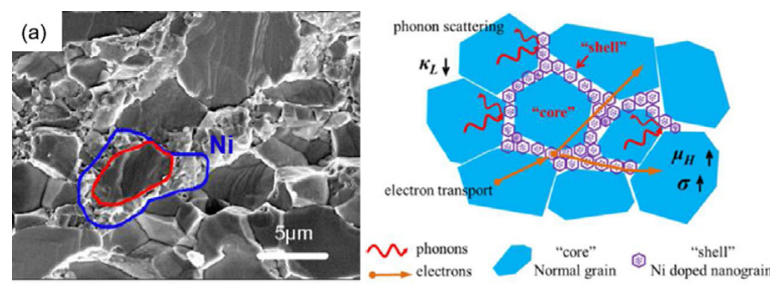

(b) $\ln _{x} \mathrm{Ce}_{y} \mathrm{Co}_{4} \mathrm{Sb}_{12+z} / \operatorname{lnSb}$
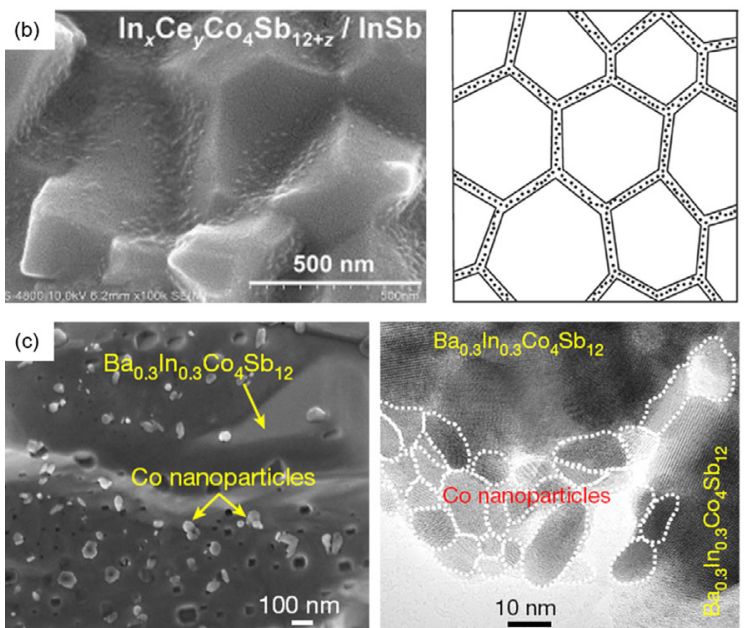

Fig. 6. (a) Core-shell 구조를 가지는 $\mathrm{Ni}$-doped $\mathrm{Yb}_{0.2} \mathrm{Co}_{4} \mathrm{Sb}_{12}$ 화합 물의 SEM 이미지 ${ }^{9}$. (b) InSb 나노구조체의 in-situ 형성을 통해 합성된 $\ln _{\mathrm{x}} \mathrm{Ce}_{\mathrm{y}} \mathrm{Co}_{4} \mathrm{Sb}_{12} / \mathrm{lnSb}$ 나노복합체의 SEM 이미지 10). (c) $\mathrm{Co}$ 나노입자가 분산된 $\mathrm{Ba}_{0.3} \mathrm{In}_{0.3} \mathrm{CO}_{4} \mathrm{Sb}_{12}$ 나노복합체의 SEM 및 TEM 이미지 ${ }^{111}$.

$\mathrm{Yb}_{0,2} \mathrm{Co}_{4} \mathrm{Sb}_{12}$ 결정립을 둘러싸고 있는 core-shell 구조 를 가지는 샘플을 제작하였으며, 도핑을 통한 캐리어 농 도의 조절과 core-shell 구조 계면에서의 포논 산란을 통 해 $723 \mathrm{~K}$ 에서 $Z T=1.07$ 을 보고하였다(Fig. 6(a) $)^{9)}$. 2017년에 H. Li는 급속응고법을 통해 2차상 나노입자를 결정립계에 분산하는 기술을 확보하였으며 포논 산란을 극대화하여 $800 \mathrm{~K}$ 에서 $Z \mathrm{~T}=1.5$ 를 보고하였다(Fig. $6(\mathrm{~b}))^{10)}$. 2017년에 W. Zhao는 superparamagnetic 특 성을 가지는 $\mathrm{Co}$ 나노입자를 $\mathrm{Ba}_{0.3} \mathrm{In}_{0.3} \mathrm{Co}_{4} \mathrm{Sb}_{12}$ 에 분산시 켜 $n$-type $0.2 \mathrm{Co} / \mathrm{Ba}_{0.3} \mathrm{In}_{0.3} \mathrm{CO}_{4} \mathrm{Sb}_{12}$ 나노복합체를 제작 하였으며, 전자와 포논의 전도를 조절하여 $850 \mathrm{~K}$ 에서 $Z T=1.8$ 을 달성하였다(Fig. 6(c) $)^{11)}$.

또한, $\mathrm{CoSb}_{3}$ 계 소재와 2차원 물질을 복합화하여 계면 에서 발생하는 포논 산란을 통해 열전도도를 감소시켜 열 전성능지수를 높이려는 연구도 보고된 바 있다. P. Zong 은 n-type $\mathrm{Yb}_{0.27} \mathrm{Co}_{4} \mathrm{Sb}_{12}$ 와 $p$-type $\mathrm{Ce}_{0.85} \mathrm{Fe}_{3} \mathrm{CoSb}_{12}$ 에
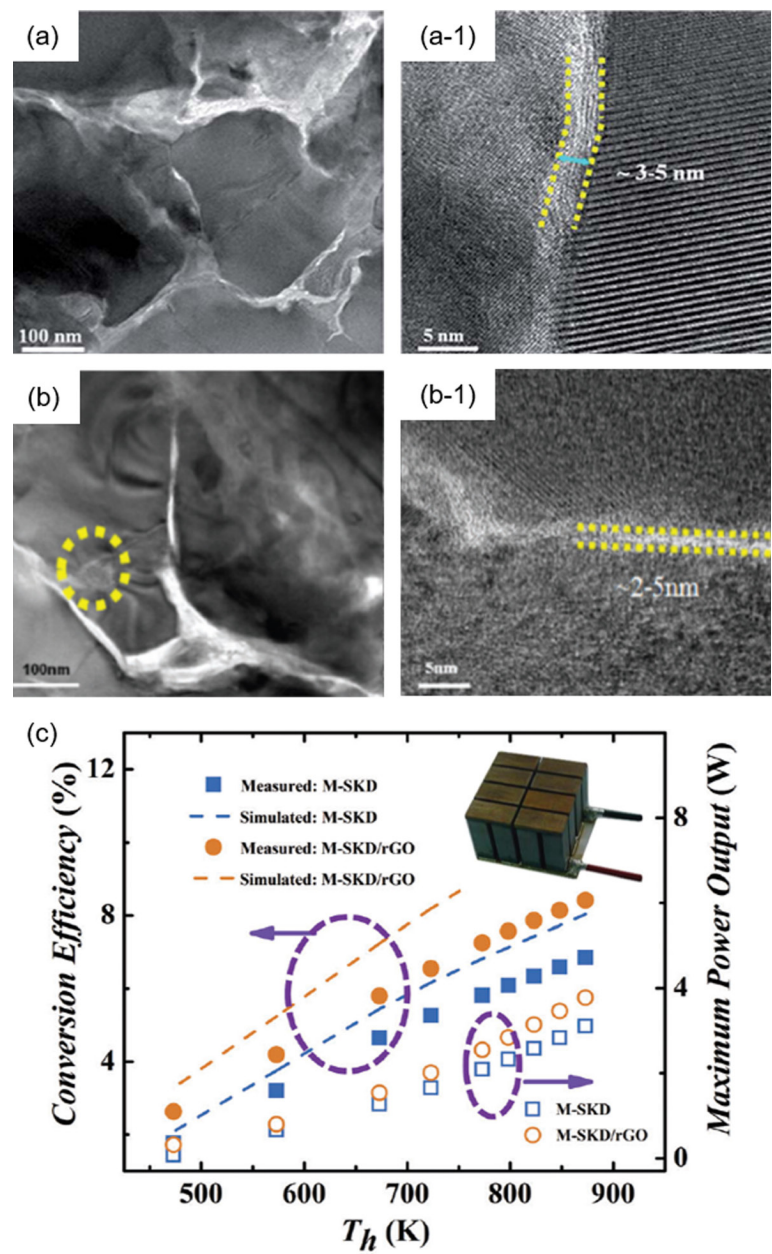

Fig. 7. (a) n-type $\mathrm{Yb}_{0.27} \mathrm{Co}_{4} \mathrm{Sb}_{12}$ 와 (b) p-type $\mathrm{Ce}_{0.85} \mathrm{Fe}_{3} \mathrm{CoSb}_{12}$ 에 $\mathrm{RGO}$ 를 첨가하여 제작한 나노복합체의 $\mathrm{TEM}$ 이미지 12,13 . (c) n-type $\mathrm{Yb}_{0.27} \mathrm{Co}_{4} \mathrm{Sb}_{12} / 0.72$ vol\% RGO 샘플과 $p$-type $\mathrm{Ce}_{0.85} \mathrm{Fe}_{3} \mathrm{CoSb}_{12} / 1.4 \mathrm{vol} \% \mathrm{RGO}$ 샘플을 이용하여 제작한 8 쌍 모듈의 hot side 온도에 대한 변환 효율 및 최대 전력(13.

$\mathrm{RGO}$ (reduced graphene oxide)를 첨가하여 전기전도도 의 손실 없이 열전도도만 감소시켜 각각 $Z T=$ $1.51\left(\mathrm{Yb}_{0.27} \mathrm{Co}_{4} \mathrm{Sb}_{12} / 0.72\right.$ vol\% RGO 샘플, $\left.850 \mathrm{~K}\right)$ 과 $1.06\left(\mathrm{Ce}_{0.85} \mathrm{Fe}_{3} \mathrm{CoSb}_{12} / 1.4\right.$ vol\% RGO 샘플, $\left.700 \mathrm{~K}\right)$ 을 달 성하였다(Fig. $7(\mathrm{a}, \mathrm{b}))^{12,13)}$. n-type $\mathrm{Yb}_{0.27} \mathrm{CO}_{4} \mathrm{Sb}_{12} / 0.72$ vol\% RGO 샘플과 $p$-type $\mathrm{Ce}_{0.85} \mathrm{Fe}_{3} \mathrm{CoSb}_{12} / 1.4 \mathrm{vol} \%$ $\mathrm{RGO}$ 샘플을 이용하여 제작한 8쌍 모듈의 변환 효율 및 최대 전력을 Fig. 7(c)에 나타내었다. $\Delta T=577 \mathrm{~K}(\mathrm{hot}$ side 온도: $873 \mathrm{~K}$, cold side 온도: $296 \mathrm{~K})$ 에서 $8.4 \%$ 의 변환 효율과 $3.8 \mathrm{~W}$ 의 최대 전력을 달성하였는데. 이는 

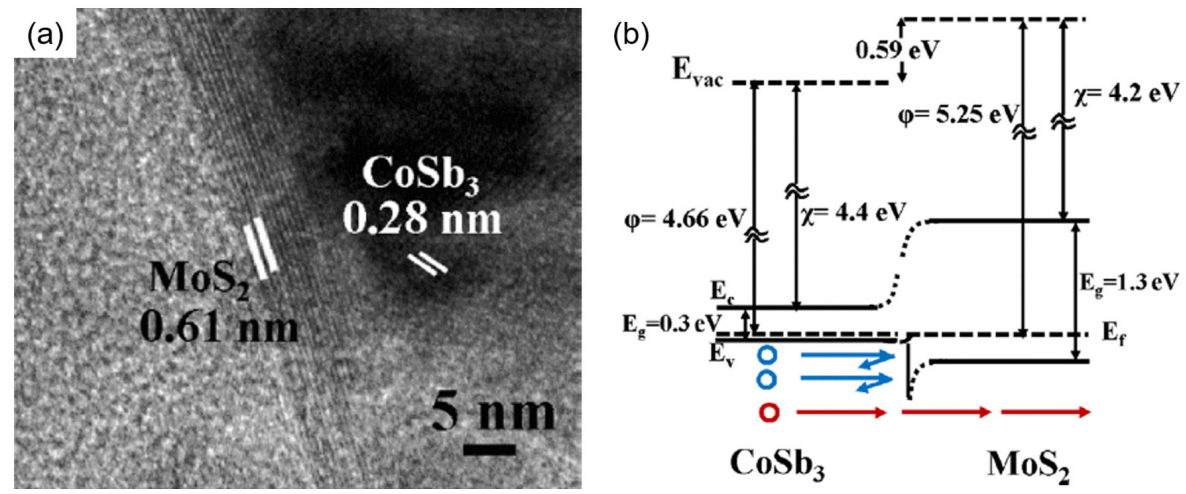

Fig. 8. (a) p-type $\mathrm{CoSb}_{3} / \mathrm{MoS}_{2}$ 나노복합체의 TEM 이미지. (b) $\operatorname{CoSb}_{3}$ 와 $\mathrm{MoS}_{2}$ 간의 band alignment 모식도 ${ }^{14)}$.

그동안 보고된 열전모듈 중에서 가장 높은 변환 효율을 보고한 것으로 의의가 있다 ${ }^{13)}$.

특히 $\mathrm{CoSb}_{3}-\mathrm{MoS}_{2}$ 복합체의 경우(Fig. 8), $\mathrm{CoSb}_{3}$ 와 $\mathrm{MoS}_{2}$ 간의 밴드갭 에너지 차이로 인해 생성되는 potential barrier가 low energy hole의 이동을 제한하 는 carrier filtering effect를 통해 파워팩터가 증가하고, $\mathrm{CoSb}_{3}$ 와 $\mathrm{MoS}_{2}$ 의 계면에서 포논을 산란시켜 열전도도가 감소하여 $p$-type $\mathrm{CoSb}_{3} / 3 \mathrm{wt} \% \mathrm{MoS}_{2}$ 나노복합체에서 $Z T=0.53(600 \mathrm{~K})$ 을 나타내었다 ${ }^{14)}$.

또한 $p$-type $\mathrm{CoSb}_{3}$ 계 소재의 경우, $n$-type 소재에 비해 높은 열전도도를 가지고 있어 낮은 열전성능을 나타 내는 문제점을 가지고 있는데 ${ }^{15}$, 이러한 점을 해결하기 위해 과량의 $\mathrm{Sb}_{\text {를 }} \mathrm{Ce}_{0.8} \mathrm{Fe}_{3} \mathrm{CoSb}_{12}$ 에 첨가한 뒤 액상소결
을 통해 배출시켜 포논산란센터로 작용하는 dislocation array를 결정립계에 유도하여 열전도도를 감소시키는 연 구가 보고되었으며, $723 \mathrm{~K}$ 에서 $Z T=1.1$ 을 나타내었다 (Fig. 9) ${ }^{16)}$.

국내에서는 국립한국교통대학교와 한국세라믹기술원 이 도핑과 rattling 효과가 skutterudite계 소재의 열전 특성에 미치는 영향에 대해 체계적인 연구를 진행하였으 며 ${ }^{17-30)}$, 최근에는 S. Lee가 급속응고법을 이용하여 나노 사이즈의 결정립을 가지는 샘플을 제작하여 $n$-type $\mathrm{In}_{0,12} \mathrm{Yb}_{0,20} \mathrm{Co}_{4,00} \mathrm{Sb}_{11.84}$ 샘플과 $p$-type $\mathrm{Ce}_{0.91} \mathrm{Fe}_{3,40} \mathrm{Co}_{0,59}$ $\mathrm{Sb}_{12,14}$ 샘플에서 각각 $Z T=1.48(800 \mathrm{~K}), 1.15(750 \mathrm{~K})$ 을 달성하였다 ${ }^{31}$. Table 1 에 skutterudite계 열전소재에 대 한 연구결과를 정리하여 나타내었다.
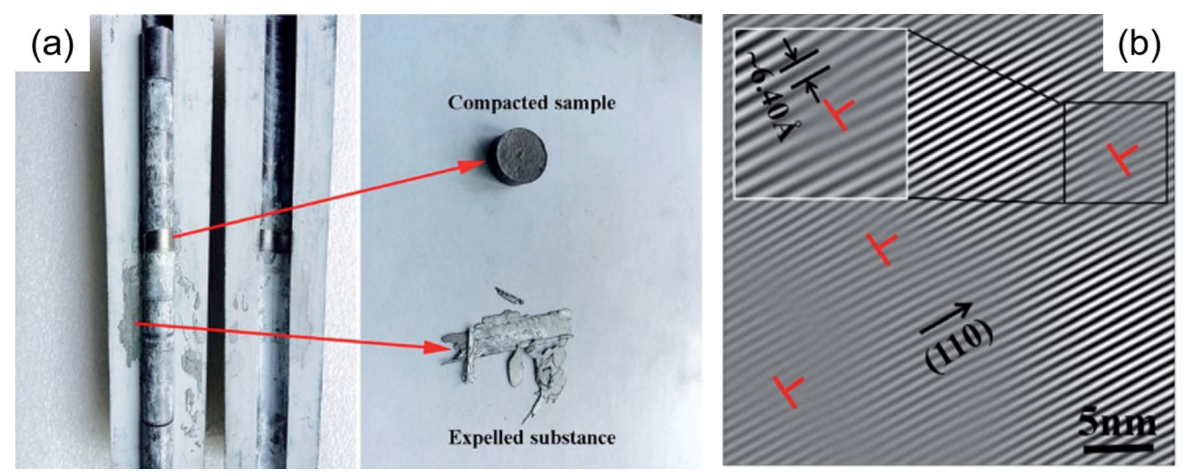

Fig. 9. (a) Sb 과량 첨가를 통한 액상소결공정 후의 $\mathrm{Ce}_{0.8} \mathrm{Fe}_{3} \mathrm{CoSb}_{12}$ 샘플 이미지. (b) 결정립계에 존재하는 dislocation array를 나타내는 TEM 이미지 ${ }^{16)}$. 
Table 1. Skutterudite계 소재 연구동향

\begin{tabular}{|c|c|c|c|c|}
\hline Type & Materials & Maximum $Z T$ & Temp. [K] & Ref. \\
\hline \multirow{8}{*}{$\mathrm{n}$} & $\mathrm{Yb}_{0.3} \mathrm{Co}_{4} \mathrm{Sb}_{12}$ & 1.5 & 850 & 7) \\
\hline & $\mathrm{Ba}_{0.08} \mathrm{La}_{0.05} \mathrm{Yb}_{0.04} \mathrm{Co}_{4} \mathrm{Sb}_{12}$ & 1.7 & 850 & 8) \\
\hline & $0.2 \mathrm{wt} \% \mathrm{Ni}$-doped $\mathrm{Yb}_{0.2} \mathrm{Co}_{4} \mathrm{Sb}_{12}$ & 1.07 & 723 & 9) \\
\hline & $\mathrm{In}_{0.2} \mathrm{Ce}_{0,15} \mathrm{CO}_{4} \mathrm{Sb}_{12} / \mathrm{InSb}$ & 1.5 & 800 & 10) \\
\hline & $0.2 \mathrm{Co} / \mathrm{Ba}_{0.3} \mathrm{In}_{0.3} \mathrm{Co}_{4} \mathrm{Sb}_{12}$ & 1.8 & 850 & 11) \\
\hline & $\mathrm{Yb}_{0.27} \mathrm{Co}_{4} \mathrm{Sb}_{12} / 0.72$ vol\% RGO & 1.51 & 850 & 12) \\
\hline & $\mathrm{In}_{0.2} \mathrm{Yb}_{0.1} \mathrm{Co}_{4} \mathrm{Sb}_{12}$ & 1.26 & 760 & 19) \\
\hline & $\mathrm{In}_{0.12} \mathrm{Yb}_{0.20} \mathrm{Co}_{4,00} \mathrm{Sb}_{11,84}$ & 1.48 & 800 & 31) \\
\hline \multirow{5}{*}{$\mathrm{p}$} & $\mathrm{Ce}_{0.85} \mathrm{Fe}_{3} \mathrm{CoSb}_{12} / 1.4$ vol\% RGO & 1.06 & 700 & 13) \\
\hline & $\mathrm{CoSb}_{3} / 3 \mathrm{wt} \% \mathrm{MoS}_{2}$ & 0.53 & 600 & 14) \\
\hline & $\mathrm{Ce}_{0.8} \mathrm{Fe}_{3} \mathrm{CoSb}_{12}$ & 1.1 & 723 & 16) \\
\hline & $\mathrm{Nd}_{0.9} \mathrm{Fe}_{3.5} \mathrm{Co}_{0.5} \mathrm{Sb}_{12}$ & 0.91 & 723 & 25) \\
\hline & $\mathrm{Ce}_{0.91} \mathrm{Fe}_{3.40} \mathrm{Co}_{0.59} \mathrm{Sb}_{12.14}$ & 1.15 & 750 & 31) \\
\hline
\end{tabular}

\section{3. 산화물계 열전소재기술 동향}

산업적으로 많이 연구되고 있는 대표적인 폐열원인 자 동차 배기가스의 경우 $750 \mathrm{~K}$ 이하의 열이 발생하지만, 폐기물 소각로 등과 같이 그 이상 온도의 폐열을 활용하 기 위해서는 고온에서 상이 안정한 열전소재가 필요하며 대표적으로 산화물계 열전소재가 유망한 소재 중 하나로 여겨져 왔다.

대표적인 $n$-type 산화물계 열전소재인 $\mathrm{ZnO}$ 계 및
$\mathrm{ZnO}-\mathrm{In}_{2} \mathrm{O}_{3}$ 계 소재는 1996년에 최초로 열전특성이 보고 된 이래 $(Z T=0.3,1,273 \mathrm{~K})^{32,33)}$, 유망한 산화물계 열전 소재로 주목받아왔다. $\mathrm{ZnO}$ 계 소재는 도핑을 통해 높은 파워팩터를 얻을 수 있는 반면 구조적 특성으로 인해 상 온에서 $60 \mathrm{~W} / \mathrm{mK}$ 정도의 높은 열전도도를 가지기 때문에 효율 향상을 위하여 열전도도를 저감하는 것이 가장 중요 한 개발 방향이다. 최근에는 나노구조화를 통해 $\mathrm{ZnO}$ 계 소재의 열전특성을 향상시키려는 연구가 활발히 진행되 고 있는데, 2010년에 Y. Kinemuchi는 Ga-doped ZnO (a)

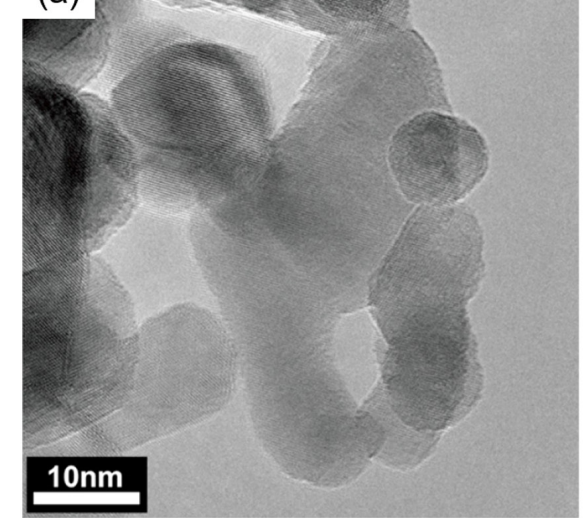

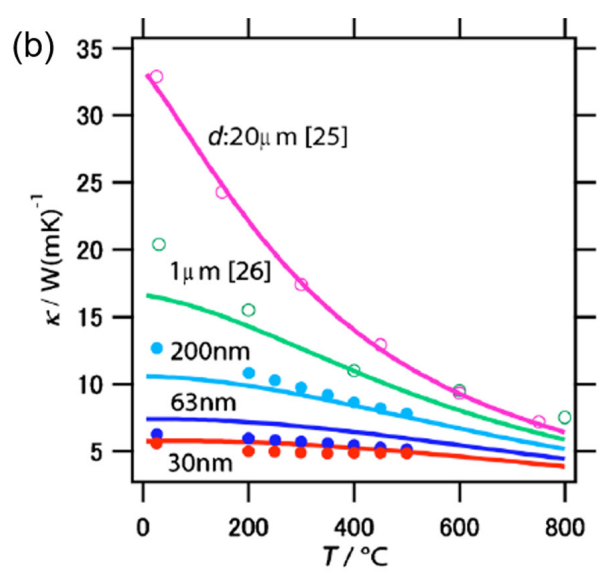

Fig. 10. (a) 나노결정립으로 구성된 Ga-doped $\mathrm{ZnO}$ 소결체의 TEM 이미지. (b) ZnO 결정립 크기에 대한 열전도도의 변화 ${ }^{34)}$. 


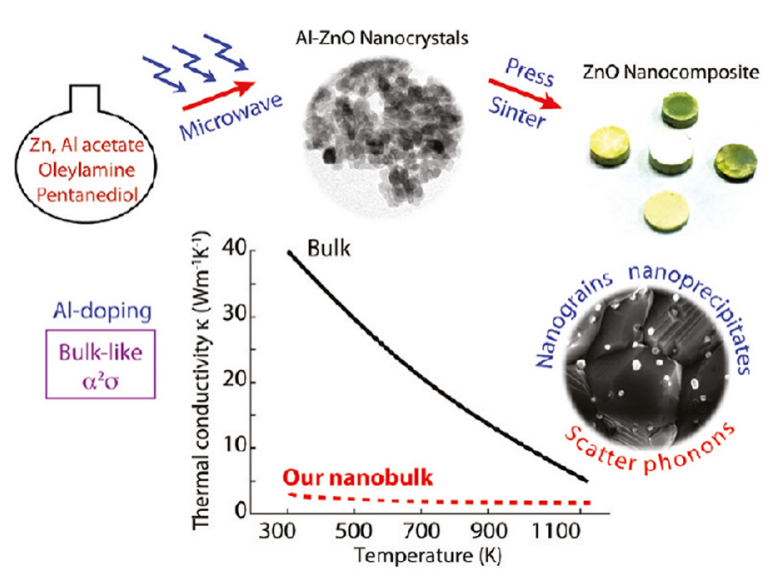

Fig. 11. $\mathrm{ZnO}$ 나노결정립과 $\mathrm{ZnAl}_{2} \mathrm{O}_{4}$ 나노석출물에서 일어나는 포논 산란을 통한 열전도도 저감 현상35).

나노입자를 소결하여 나노결정립으로 구성된 샘플을 제 작하여, 결정립 크기가 작아질수록 포논의 결정립계 산란 이 극대화 되어 열전도도가 감소한다는 것을 보고하였다 (Fig. 10) ${ }^{34)}$. 2011년에 P. Jood는 $25 \sim 250 \mathrm{~nm}$ 의 크기 를 가지는 $\mathrm{ZnO}$ 나노결정립과 $\mathrm{ZnAl}_{2} \mathrm{O}_{4}$ 나노석출물로 이 루어진 $\mathrm{Al}$-doped $\mathrm{ZnO}$ 나노복합체를 제작하여 $1,000 \mathrm{~K}$ 에서 $Z T=0.44$ 를 발표하였다. 나노결정립과 나노석출 물에서 발생하는 포논의 결정립계 산란을 통해 지금까지 보고된 $\mathrm{ZnO}$ 계 열전소재 중에서 가장 낮은 열전도도를 달 성하였으며(상온에서 $3 \mathrm{~W} / \mathrm{mK}, 1,000 \mathrm{~K}$ 에서 $1.9 \mathrm{~W} /$ $\mathrm{mK}), 1996$ 년에 M. Ohtaki가 보고한 값보다 높은 ZT를 처음으로 달성하였다(Fig. 11) ${ }^{35)}$. 또한 2017년에 D. B.
Zhang은 마이크로/나노구조체가 동시에 존재하는 hybrid-structured $\mathrm{Al}$-doped $\mathrm{ZnO}$ 샘플을 제작하여 전자와 포논의 전도를 Fig. 12 에 나타낸 것처럼 독립적으 로 제어한 결과, $1,073 \mathrm{~K}$ 에서 $Z T=0.36$ 을 보고하였다 ${ }^{36)}$. 한편, $\mathrm{CNT}$ (carbon nanotube)를 이용한 계면제어가 un-doped $\mathrm{ZnO}$ 의 열전특성에 미치는 영향에 대한 연구 가 진행되었는데, $\mathrm{ZnO}$ 가 나노결정립으로 이루어져 있음 에도 불구하고 $\mathrm{CNT}$ 첨가로 인해 $\mathrm{ZnO}-\mathrm{CNT}$ 나노복합체 는 단결정 수준의 전기적 특성을 보였으며, CNT가 추가 적인 포논산란센터로 작용함으로써 격자열전도도가 감 소함을 보였다. 그 결과 un-doped $\mathrm{ZnO}$ 중에서는 가장 높은 값인 $Z T=0.06(970 \mathrm{~K})$ 을 달성하였다(Fig. 13) $)^{37)}$. 이를 통해 탄소나노물질을 이용한 계면제어를 통해 $\mathrm{PGEC}$ 개념을 $\mathrm{ZnO}$ 계 소재에서 실현 가능하다는 것을 알 수 있고, 향후 도핑을 통한 캐리어 농도 최적화 기술 을 함께 접목할 경우 열전성능지수의 향상이 기대되는 대목이다.

대표적인 $p$-type 산화물계 열전소재로는 $\mathrm{NaCO}_{2} \mathrm{O}_{4}$, $\mathrm{Ca}_{3} \mathrm{Co}_{4} \mathrm{O}_{9}, \mathrm{Bi}_{2} \mathrm{Sr}_{3} \mathrm{Co}_{2} \mathrm{O}_{9}$ 등의 소재가 있는데, $\mathrm{NaCo}_{2} \mathrm{O}_{4}$ 와 $\mathrm{Bi}_{2} \mathrm{Sr}_{3} \mathrm{Co}_{2} \mathrm{O}_{9}$ 는 고온 노출 시 $\mathrm{Na}$ 와 $\mathrm{Bi}$ 가 쉽게 휘발되는 문 제점으로 인해 $\mathrm{Ca}_{3} \mathrm{CO}_{4} \mathrm{O}_{9}$ 계 소재가 가장 적합한 고온용 p-type 열전소재로 주목받아왔다 ${ }^{38-40)} . \mathrm{Ca}_{3} \mathrm{Co}_{4} \mathrm{O}_{9}$ 의 결 정구조는 monoclinic subsystem의 $\mathrm{CoO}_{2}$ sheet와 $\mathrm{Ca}_{2} \mathrm{CoO}_{3}$ block이 c축을 따라 번갈아 적층되는 구조로, 두 층의 격자상수 차이로 인해 $\left(\vec{b}_{\mathrm{CoO}_{2}}=2.8238 \AA\right.$,
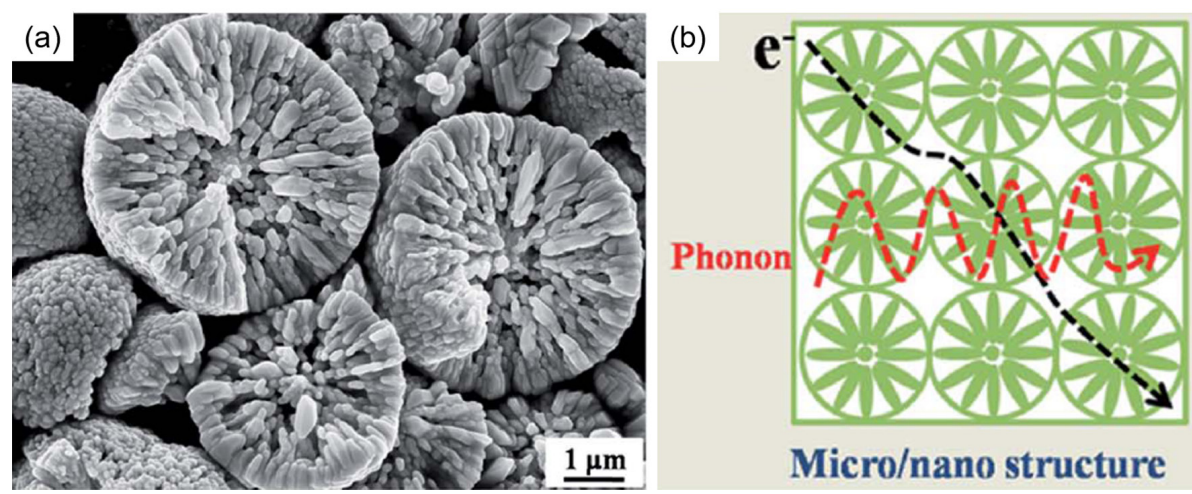

Fig. 12. (a) 마이크로/나노구조체로 이루어진 Al-doped ZnO 소결체의 SEM 이미지. (b) Hybrid-structured Al-doped ZnO에서의 전자/포 논 전도에 대한 모식도 ${ }^{36)}$. 


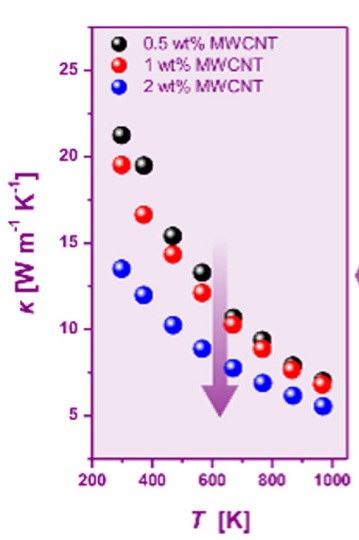

Phonon-Glass

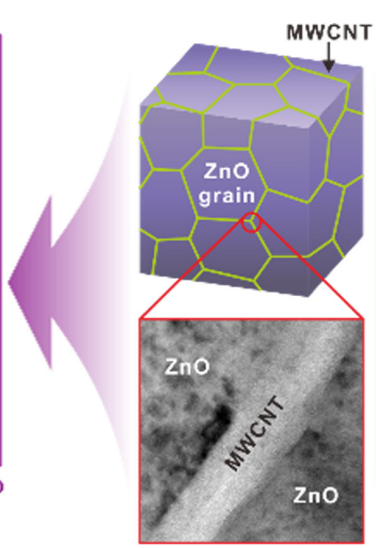

ZnO-MWCNT nanocomposite

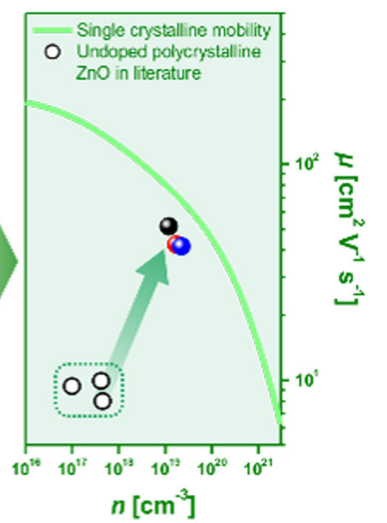

Electron-Crystal

Fig. 13. CNT를 이용한 계면제어를 통해 ZnO계 열전소재에서의 PGEC 개념 실현을 나타내는 모식도가.

$\vec{b}_{\mathrm{Ca}_{2} \mathrm{CoO}_{3}}=4.5582 \AA$ ) misfit에 기인한 이방성을 나타낸 다(Fig. 14) ${ }^{41,42)}$. 이로 인해 단결정 $\mathrm{Ca}_{3} \mathrm{Co}_{4} \mathrm{O}_{9}$ 의 $\mathrm{in}-$ plane(ab plane) 방향과 out-of-plane(c axis) 방향의 전기전도도와 제벡계수는 서로 다른 값을 가지게 된달) 만약 in-plane 방향으로의 전류가 흐를 경우 전도층인 $\mathrm{CoO}_{2}$ sheet를 따라 전류가 흐르게 되므로 out-ofplane 방향보다 높은 전기전도도를 얻을 수 있기 때문에, $\mathrm{Ca}_{3} \mathrm{Co}_{4} \mathrm{O}_{9}$ 계 소재에서의 $Z T$ 는 in-plane 방향으로 측정 한다. 2013년에 M. Shikano는 플럭스 방법을 통해 합성 한 단결정 $\mathrm{Ca}_{3} \mathrm{Co}_{4} \mathrm{O}_{9}$ 에서 $Z T=0.87(973 \mathrm{~K})$ 를 보고하였 으며4), 2006년에 M. Mikami는 Bi가 도핑된 단결정
$\mathrm{Ca}_{3} \mathrm{Co}_{4} \mathrm{O}_{9}$ 를 제작하여 $973 \mathrm{~K}$ 에서 $Z \mathrm{~T}=0.90$ 을 보고하였 다45). 하지만 단결정 $\mathrm{Ca}_{3} \mathrm{Co}_{4} \mathrm{O}_{9}$ 제작은 느린 냉각속도로 인해 $(\sim 1 \mathrm{~K} / \mathrm{h})$ 장시간 공정이 불가피하여 고상반응을 통 한 다결정 $\mathrm{Ca}_{3} \mathrm{Co}_{4} \mathrm{O}_{9}$ 의 열전특성에 대한 연구들이 진행되 었고, 열전성능의 향상을 위해 나노구조체의 도입이 고려 되었다. 2010년에 T. Yin은 electrospinning 공정으로 합성된 $\mathrm{Ca}_{3} \mathrm{Co}_{4} \mathrm{O}_{9}$ 나노파이버를 소결하여 제작한 소결체 에서 $Z T=0.4(975 \mathrm{~K})$ 를 보고하였고(Fig. 15) ${ }^{46)}, 2011$ 년 에 N. V. Nong은 $\mathrm{Ag}$ 와 $\mathrm{Lu}$ 이 도핑된 다결정 $\mathrm{Ca}_{3} \mathrm{Co}_{4} \mathrm{O}_{9}$ 을 제작하여, 결정립에 생성되는 $\mathrm{Ag}$-rich phase의 나노 인클루젼 형성을 통해 $\mathrm{Ca}_{2,8} \mathrm{Ag}_{0.05} \mathrm{Lu}_{0.15} \mathrm{Co}_{4} \mathrm{O}_{9}$ 샘플에서 (a)

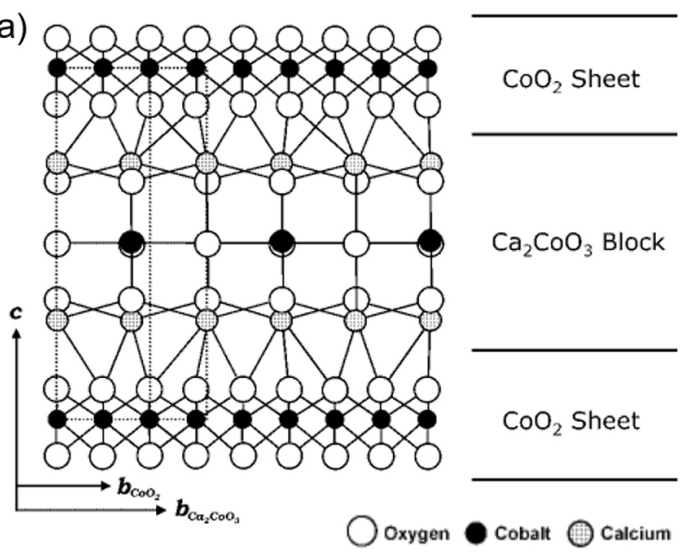

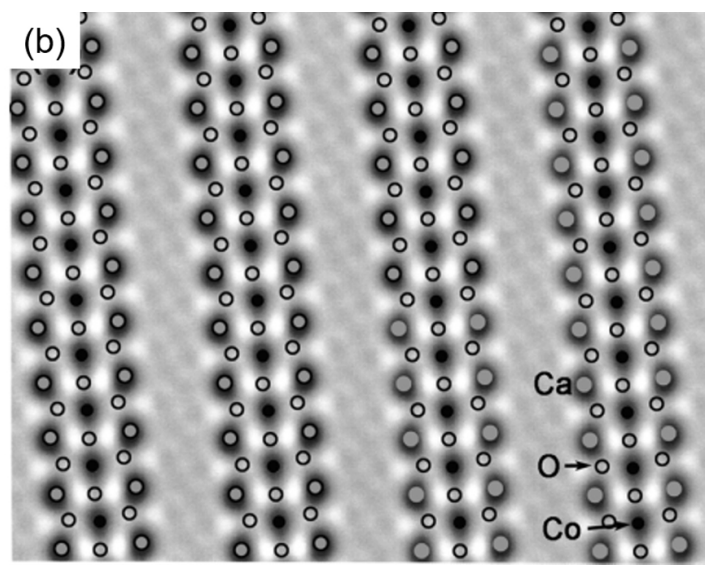

Fig. 14. (a) a축에서 바라본 $\mathrm{Ca}_{3} \mathrm{CO}_{4} \mathrm{O}_{9}$ 결정구조의 모식도. (b) $\mathrm{Ca}_{2} \mathrm{CoO}_{3}$ 블록의 금속 원자 배열(Ca-Co-Ca)을 나타내는 [110]방향의 고분해 능 TEM 이미지 $\left.\right|^{41,42}$. 


\section{특 집 므남우현, 신원호, 조중영, 서원선}
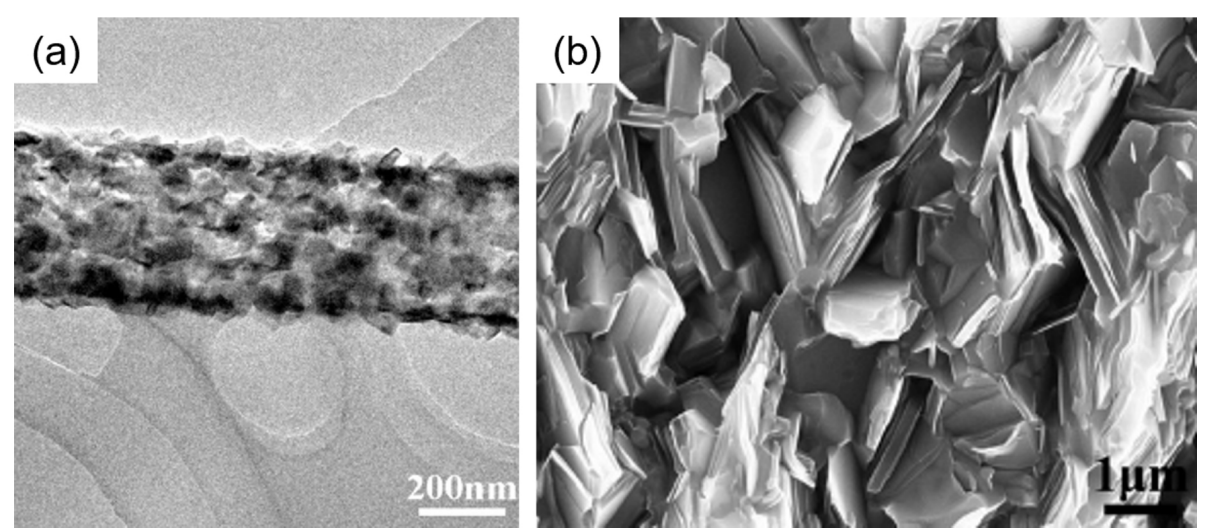

Fig. 15. (a) Electrospinning 공정을 통해 합성된 $\mathrm{Ca}_{3} \mathrm{CO}_{4} \mathrm{O}_{9}$ 나노파이버의 TEM 이미지. (b) $\mathrm{Ca}_{3} \mathrm{CO}_{4} \mathrm{O}_{9}$ 나노파이버를 소결한 소결체의 $\mathrm{SEM}$ 이 미지. ${ }^{46)}$.
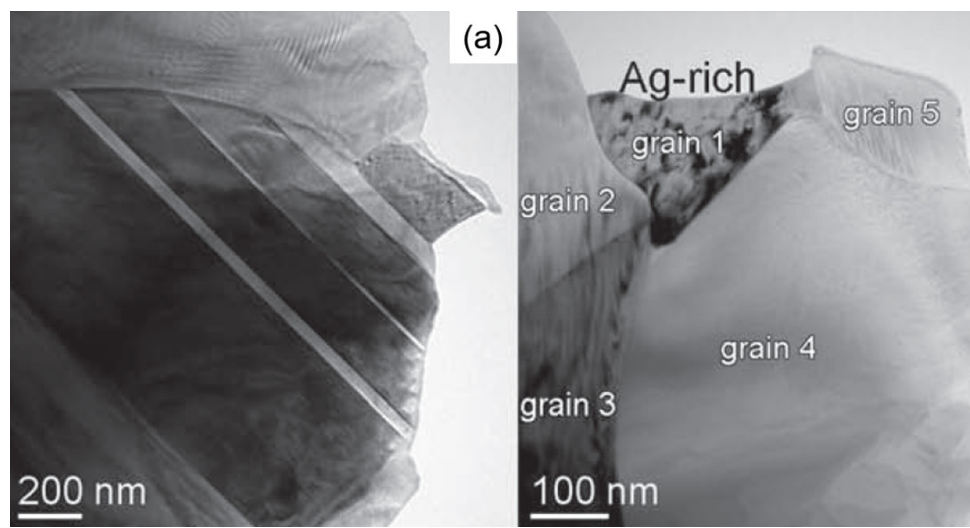

(b)

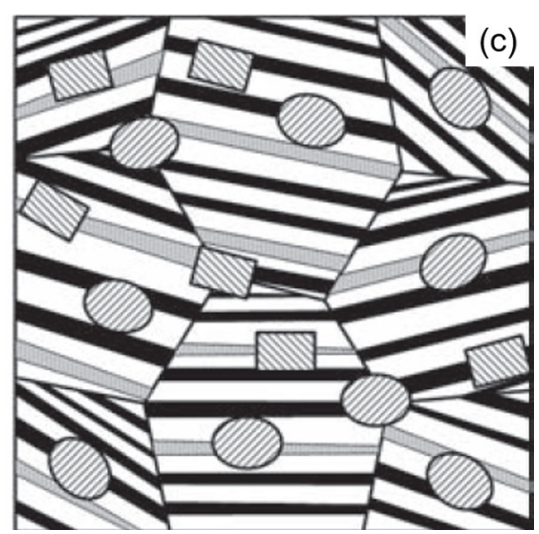

Fig. 16. (a, b) Ag-rich phase의 나노인클루젼이 형성된 $\mathrm{Ca}_{2.8} \mathrm{Ag}_{0.05} \mathrm{Lu}_{0.15} \mathrm{CO}_{4} \mathrm{O}_{9}$ 샘플의 TEM 이미지. (b) 나노인클루젼과 $\mathrm{Ca}_{3} \mathrm{CO}_{4} \mathrm{O}_{9}$ 의 라멜라 구조로 구성되는 $\mathrm{Ca}_{2.8} \mathrm{Ag}_{0.05} \mathrm{Lu}_{0.15} \mathrm{CO}_{4} \mathrm{O}_{9}$ 샘플의 미세구조에 대한 모식도 ${ }^{47}$.

보고된 다결정 $\mathrm{Ca}_{3} \mathrm{CO}_{4} \mathrm{O}_{9}$ 의 $Z T$ 값 중에 가장 높은 값인 $Z T=0.61(1,118 \mathrm{~K})$ 을 달성하였다(Fig. 16) ${ }^{47}$.

\section{4. 결론}

열전변환기술은 열과 전기에너지를 고체 상태에서 직 접적으로 변환할 수 있는 유일한 에너지 기술로 고효율 열전소재의 개발이 열전모듈의 변환효율을 결정하게 된 다. 열전발전 모듈은 중 · 고온 영역에 해당하는 광범위한 온도의 열원에 적용 가능이 가능한 기술로 응용범위와 시 장성이 아주 높다. 본고에서 살펴본 선행연구들처럼 고효 율 중·고온용 열전발전소재의 개발을 위해서는 열전성 능지수를 구성하는 인자들의 상관관계를 약화시키기 위
해 나노기술을 통한 구조 제어가 필수적이다. 대표적인 중·고온용 열전소재인 skutterudite계 소재와 산화물 계 소재에서 파워팩터의 감소없이 열전도도를 제어하기 위해 다양한 종류의 나노구조체의 첨가와 탄소나노물질 을 이용한 계면제어 기술들이 고려되었다.

열전소재의 물성 개선과 더불어 현재 우수한 열전성능 을 나타내는 열전소재들은 희소원소 및 독성원소를 포함 하고 있어 이를 대체하기 위해 친환경 저가 원소로 구성 된 신조성의 열전소재의 개발이 요구된다. 최근 여러 방 법을 통해 열전소재의 성능은 급격한 성장을 맞이하였으 나, 이런 고효율 열전소재를 실제 활용하기 위한 모듈화 연구는 아직 미비한 상황이다. 향후 우리나라가 세계 열 전시장을 선도하기 위해서는 열전소재기술 뿐만 아니라 
열전모듈기술에 대한 지속적인 연구 및 투자가 이루어져 야만 하고, 이를 통해서만 열전변환기술의 폭넓은 활용이 가능할 것이라 예상한다.

\section{참고문헌}

1. J. -F. Li, W. -S. Liu, L. -D. Zhao and M. Zhou,"Highperformance nanostructured thermoelectric materials" NPG Asia Mater., 2 152-8 (2010).

2. J. Snyder and E. S. Toberer, "Complex thermoelectric materials" Nat. Mater, 7 105-14 (2008).

3. S. Lee, J. A. Bock, S. Trolier-McKinstry, and C. A. Randall, "Ferroelectric-thermoelectricity and Mott transition of ferroelectric oxides with high electronic conductivity" J. Euro. Ceram. Soc., 32 3971-88 (2012).

4. G. A. Slack, "CRC Handbook of Thermoelectric"pp. 407, CRC Press, Boca Raton, 1995.

5. M. Rull-Bravo, A. Moure, J. F. Fernandez, and M. Martin-Gonzalez, "Skutterudites as thermoelectric materials: revisited" RSC Adv., 5 41653-67 (2015).

6. W. Zhao, P. Wei, Q. Zhang, H. Peng, W. Zhu, D. Tang, J. Yu, H. Zhou, Z. Liu, X. Mu, D. He, J. Li, C. Wang, X. Tang, and J. Yang, "Multi-localization transport behaviour in bulk termoelectric materials" Nat. Commun, 66197 (2015).

7. S. Wang, J. R. Salvador, J. Yang, P. Wei, B. Duan, and J. Yang, "High-performance $n$-type $\mathrm{Yb}_{\mathrm{x}} \mathrm{Co}_{4} \mathrm{Sb}_{12}$. from partially filled skutterudites towards composite thermoelectrics" NPG Asia Mater, 8 e285 (2016).

8. X. Shi, J. Yang, J. R. Salvador, M. Chi, J. Y. Cho, H. Wang, S. Bai, J. Yang, W. Zhang, and L. Chen, "Multiple-Filled Skutterudites: High Thermoelectric Figure of Merit through Separately Optimizing Electrical and Thermal Transports" J. Am. Chem. Soc., 133 7837-46 (2011).

9. L. Fu, J. Yang, J. Peng, Q. Jiang, Y. Xiao, Y. Luo, D. Zhang, Z. Zhou, M. Zhang, Y. Cheng, and F. Cheng, "Enhancement of Thermoelectric Properties of $\mathrm{Yb}$-filled Skutterudites by Ni Induced "Core-shell Structure" J. Mater. Chem. A, 31010-6 (2015).

10. H. Li, X. Su, X. Tang, Q. Zhang, C. Uher, G. J. Snyder, andU. Aydemir, "Grain boundary engineering with nano-scale InSb producing high performance $\mathrm{In}_{x} \mathrm{Ce}_{y} \mathrm{CO}_{4} \mathrm{Sb}_{12+z}$ skutterudite thermoelectrics" $J$. Materiomics, 3 273-9 (2017).

11. W. Zhao, Z. Liu, Z. Sun, Q. Zhang, P. Wei, X Mu, H.
Zhou, C. Li, S. Ma, D. He, P. Ji, W. Zhu, X. Nie, X. Su, X. Tang, B. Shen, X. Dong, J. Yang, Y. Liu, and J. Shi, "Superparamagnetic enhancement of thermoelectric performance" Nature, 549 247-51 (2017).

12. P.-A. Zong, X, Chen, Y. Zhu, Z. Liu, Y. Zeng, and L. Chen,"Construction of a 3D-rGO networkwrapping architecture in a YbyCo4Sb12/rGO composite for enhancing the thermoelectric performance" J. Mater. Chem. A, 3 8643-9 (2015).

13. P. - A. Zong, R. Hanus, M. Dylla, Y. Tang, J. Liao, Q. Zhang, G. J. Snyder, and L. Chen,"Skutterudite with graphene-modified grain-boundary complexion enhances zT enabling high-efficiency thermoelectric device" Energy Environ. Sci., 10 183-91 (2017).

14. S. Yadav, S. Chaudhary, and D. K. Pandya, "Incorporation of $\mathrm{MoS}_{2}$ nanosheets in $\mathrm{CoSb}_{3}$ matrix as an efficient novel strategy to enhance its thermoelectric performance” Appl. Surf, Sci., 435 1265-72 (2018).

15. F. Qiu, J. Yang, R. H. Liu, X. Shi, X. Y. Huang, G. J. Snyder, W. Zhang, and L. D. Chen, "Hightemperature electrical and thermal transport properties of fully filled skutterudites $\mathrm{RFe}_{4} \mathrm{Sb}_{12}(\mathrm{R}=$ Ca, Sr, Ba, La, Ce, Pr, Nd, Eu, and Yb)" J. Appl. D Phy,., 109063713 (2011).

16. X. Meng, Y. Liu, B. Cui, D. Qin, J. Cao, W. Liu, Z. Liu, W. Cai, and J. Sui,"High thermoelectric performance of single phase $\mathrm{p}$-type cerium-filled skutterudites by dislocation engineering" $J$. Mater. Chem. A, 6 20128-37 (2018).

17. R. C. Mallik, J.-Y. Jung, S.-C. Ur, and I.-H. Kim, "Thermoelectric Properties of $\mathrm{In}_{2} \mathrm{CO}_{4} \mathrm{Sb}_{12}$ Skutterudites" Met. Mater. Int, 14 223-8 (2008).

18. J.-Y. Jung, K. - H. Park, and I. - H. Kim, "Thermoelectric and Transport Properties of In-filled and $\mathrm{Ni}$-doped $\mathrm{CoSb}_{3}$ Skutterudites" J. Korean Phys. Soc., 57 773-7 (2010).

19. J.-K. Lee, S.-M. Choi, W.-S. Seo, D.-I. Cheong, and I. -H. Kim, "Determination of the Thermoelectric Properties in Filled-Skutterudite Systems by Controlling the Process Variables" Jpn. J. Appl. Phys., 51 09ML02 (2012).

20. J.-K. Lee, S.-M. Choi, W.-S. Seo, Y.-S. Lim, H. - L. Lee, and I. -H. Kim, "Thermoelectric properties of Spark Plasma Sintered $\mathrm{In}_{x} \mathrm{Yb}_{y} \mathrm{La}_{0,3-x-y} \mathrm{CO}_{4} \mathrm{Sb}_{12}$ skutterudite system" Renew. Energ., 42 36-40 (2012).

21. S.-Y. Kim, S.-M. Choi, W.-S. Seo, Y. S. Lim, S. 
Lee, I. -H. Kim, and H. K. Cho, "An Optimization of Composition Ratio among Triple-Filled Atoms in $\mathrm{In}_{0,3-x-y} \mathrm{Ba}_{x} \mathrm{Ce}_{y} \mathrm{Co}_{4} \mathrm{Sb}_{12}$ System” J. Nanomater, 2013 973060 (2013).

22. K. -H. Park, W. -S. Seo, D. -K. Shin, and I. -H. Kim, "Thermoelectric Properties of $\mathrm{Yb}$-filled $\mathrm{CoSb}_{3}$ Skutterudites" J. Korean Phys. Soc., 65 491-5 (2014).

23. D.-K. Shin and I.-H. Kim, "Preparation and Thermoelectric Properties of $p$-Type $\operatorname{Pr}_{2} \mathrm{Fe}_{4-x} \mathrm{Co}_{x} \mathrm{Sb}_{12}$ Skutterudites" J. Korean Phys. Soc, 65 2071-6 (2014).

24. G.-S. Joo, D.-K. Shin, and I.-H. Kim, "Synthesis and Thermoelectric Properties of $p$-Type DoubleFilled $\mathrm{Ce}_{1-z} \mathrm{Yb}_{2} \mathrm{Fe}_{4-x} \mathrm{Co}_{x} \mathrm{Sb}_{12}$ Skutterudites" J. Electron. Mater., 45 1251-6 (2016).

25. D. -K. Shin and I.-H. Kim, "Electronic Transport and Thermoelectric Properties of $p$-Type $\mathrm{Nd}_{2} \mathrm{Fe}_{4-}$ ${ }_{x} \mathrm{Co}_{x} \mathrm{Sb}_{12}$ Skutterudites" J. Electron. Mater., 45 12349 (2016).

26. K.-M. Song, D.-K. Shin, and I.-H. Kim, "Thermoelectric Properties of $p$-Type $\mathrm{La}_{1-2} \mathrm{Pr}_{2} \mathrm{Fe}_{4-}$ ${ }_{x} \mathrm{Co}_{x} \mathrm{Sb}_{12}$ Skutterudites" J. Electron. Mater, 45 122733 (2016)

27. K.-M. Song, D. -K. Shin, K.-W. Jang, S.-M. Choi, S. Lee, W.-S. Seo, and I.-H. Kim, "Synthesis and Thermoelectric Properties of $\mathrm{Ce}_{-2} \mathrm{Pr}_{2} \mathrm{Fe}_{4-x} \mathrm{Co}_{x} \mathrm{Sb}_{12}$ Skutterudites" J. Electron. Mater., 46 2634-9 (2017).

28. D. -K. Shin and I.-H. Kim, "Thermoelectric Properties of Partially Double-filled $\left(\mathrm{Pr}_{1-z} \mathrm{Yb}_{2}\right)_{y} \mathrm{Fe}_{4-}$ ${ }_{x} \mathrm{Co}_{x} \mathrm{Sb}_{12}$ Skutterudites" J. Korean Phys. Soc., 70 591-7 (2017).

29. D. -K. Shin, K. -W. Jang, S. -M. Choi, S. Lee, W. -S. Sep, I. -H. Kim, "ChargeTransportandThermoelectric Properties of $\left(\mathrm{Nd}_{1-Z} \mathrm{Yb}_{2}\right)_{y} \mathrm{Fe}_{4-x} \mathrm{Co}_{x} \mathrm{Sb}_{12}$ Skutterudites" $J$. Electron. Mater, 47 3143-51 (2018).

30. Y. -E. Cha and I. -H. Kim, "Thermoelectric Properties of Partially Double-filled $\left(\mathrm{Ce}_{1-2} \mathrm{Nd}_{2}\right)_{y} \mathrm{Fe}_{4-x} \mathrm{CO}_{x} \mathrm{Sb}_{12}$ Skutterudites" Korean J. Met. Mater., 56 465-71 (2018).

31. S. Lee, K. H. Lee, Y.-M. Kim, H. S. Kim, G. J. Snyder, S. Baik, S. W. Kim, "Simple and efficient synthesis of nanograin structured single phase filled skutterudite for high thermoelectric performance" Acta Mater., 142 8-17 (2018).

32. M. Ohtaki, T. Tsubota, K. Eguchi, and H. Arai, "High-temperature thermoelectric properties of $\left(\mathrm{Zn}_{1-}\right.$ $\left.{ }_{x} \mathrm{Al}_{x}\right) \mathrm{O}$ ”. Appl. Phys., 79 1816-18 (1996).

33. H. Ohta, W. -S. Seo, and K. Koumoto, "Thermoelectric
Properties of Homologous Compounds in the $\mathrm{ZnO}-$ $\mathrm{In}_{2} \mathrm{O}_{3}$ System” J. Am. Ceram. Soc., 79 2193-6 (1996).

34. Y. Kinemuchi,. H. Nakano, M. Mikami, K. Kobayashi, K. Watari, and Y. Hotta, "Enhanced boundaryscattering of electrons and phonons in nanograined zinc oxide" J. Appl. Phys., 108053721 (2010).

35. P. Jood, R. J. Mehta, Y. Zhang, G. Peleckis, X. Wang, R. W. Siegel, T. Borca-Tasciuc, S. X. Dou, and G. Ramanath, "Al-Doped Zinc Oxide Nanocomposites with Enhanced Thermoelectric Properties" Nano Lett., 11 4337-42 (2011).

36. D. -B. Zhang, H. -Z. Li, B. -P. Zhang, D. -D. Liang, and M. Xia, "Hybrid-structured $\mathrm{ZnO}$ thermoelectric materials with high carrier mobility and reduced thermal conductivity" RSC Adv., 7 10855-64 (2017).

37. W. H. Nam, B. B. Kim, Y. S. Lim, K. S. Dae, W.-S. Seo, H.-H. Park, and J. Y. Lee, "Phonon-glass electron-crystals in $\mathrm{ZnO}$-multiwalled carbon nanotube nanocomposites" Nanoscale, 9 12941-8 (2017).

38. Y. Liu, Y. Lin, Z. Shi, C. Nan, "Preparation of $\mathrm{Ca}_{3} \mathrm{Co}_{4} \mathrm{O}_{9}$ and improvement of its thermoelectric properties by spark plasma sintering” J. Am. Ceram. Soc., 88 1337-40 (2005).

39. S. Altin, M. A. Aksan, A. Bayri, "High temperature spin state transitions in misfit-layered $\mathrm{Ca}_{3} \mathrm{Co}_{4} \mathrm{O}_{9}$ ” J. Alloy. Compd., 587 40-4 (2013).

40. Y. Yin, B. Tudu, and A. Tiwari, "Recent advances in oxide thermoelectric materials and modules" Vacuum, 146 356-74 (2017).

41. Y. Miyazaki, M. Onoda, T. Oku, M. Kikuchi, Y. Ishii, Y. Ono, Y. Morii, and T. Kajitani, "Modulated structure of the thermoelectric compound $\left[\mathrm{Ca}_{2} \mathrm{CoO}_{3}\right.$ ]$_{0.62} \mathrm{CoO}_{2}$ ” J. Phys. Soc. Jpn., 71 491-7 (2002).

42. W.-S. Seo, S. Lee, Y. Lee, M.-H. Lee, Y. Masuda, and K. Koumoto, "High-resolution transmission electron microscopy study of $\mathrm{Ca}_{3} \mathrm{Co}_{4} \mathrm{O}_{9}$ " J. Electron Microsc., 53 397-401 (2004).

43. A. C. Masset, C. Mihel, A, Maignan, M. Hervieu, O. Toulemonde, F. Studer, and B. Raveau, J. Hejtmanek,"Misfit-layered cobaltite with an anisotropic giant magnetoresistance: $\mathrm{Ca}_{3} \mathrm{Co}_{4} \mathrm{O}_{9}$ " Phys. Rev. B., 62 166-75 (2000).

44. M. Shikano and R. Funahashi, "Electrical and thermal properties of singlecrystalline $\left(\mathrm{Ca}_{2} \mathrm{CoO}_{3}\right)_{0.7} \mathrm{CoO}_{2}$ with a $\mathrm{Ca}_{3} \mathrm{Co}_{4} \mathrm{O}_{9}$ structure" Appl. Phys. Lett., 82 1851-3 (2003).

45. M. Mikami, K. Chong, Y. Miyazaki, T. Kajitani, T. 
Inoue, S. Sodeoka, and R. Funahashi, "Bi-substitution effects on crystal structure and thermoelectric properties of Ca3Co4O9 single crystals" Jpn. J. Appl. Phys., 45 4131-6 (2006).

46. T. Yin, D. Liu, Y. Ou, F. Ma, S. Xie, J.-F. Li, and J. $\mathrm{Li}$ "Nanocrystalline Thermoelectric $\mathrm{Ca}_{3} \mathrm{Co}_{4} \mathrm{O}_{9}$ Ceramics by Sol-Gel Based Electrospinning and Spark Plasma Sintering" J. Phys. Chem. C, 114
10061-5 (2010)

47. N. V. Nong, N. Pryds, S. Linderoth, and M. Ohtaki, "Enhancement of the Thermoelectric Performance of p-Type Layered Oxide $\mathrm{Ca}_{3} \mathrm{CO}_{4} \mathrm{O}_{9+\delta}$ Through Heavy Doping and Metallic Nanoinclusions" Adv. Mater., 23 2484-90 (2011).

\section{으남우 현

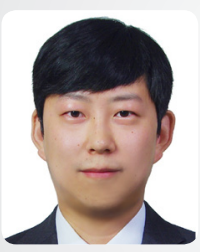 \\ ○ 2015-2017년 기초과학연구원 연구위원 \\ ○ 2017-2018년 한국세라믹기술원 박사후연구원 \\ ○ 2018-2018년 일본 Nagoya University 박사후연구원 \\ () 2018년-현재 한국세라믹기술원 에너지환경본부 선임연구원}

\section{도 조중 영}

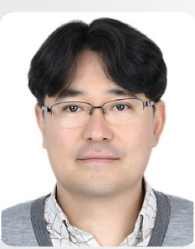

- 2008년 Louisiana State University 화학과 박사

○ 2009-2011년 General Motors 연구원

- 2012-2013년 삼성전자 종합기술원 전문연구원

- 2013-2018년 삼성전기 수석연구원

○ 2018년-현재 한국세라믹기술원 에너지환경본부 책임연구원

\section{신 원 호}

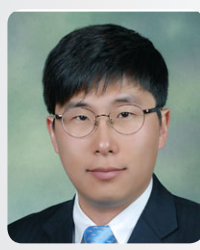

( 2011년 한국과학기술원 신소재공학과 박사

○ 2011-2011년 한국과학기술원 박사후연구원

○ 2011-2012년 한국기초과학지원연구원 박사후연구원

일 2012-2016년 삼성전자 종합기술원 전문연구원

ㅇ 2016년-현재 한국세라믹기술원 에너지환경본부 선임연구원
으서 원 선

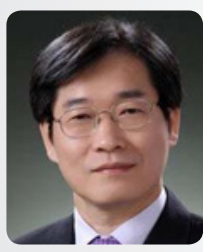

○ 1992년 일본 University of Tokyo 공업화학과 박사

- 1992-1999년 일본 Nagoya University 조교수

- 1999-2000년 일본 Nagoya University 부교수

( 2000년-현재 한국세라믹기술원 에너지환경본부장, 선임본부장, 수석연구원 